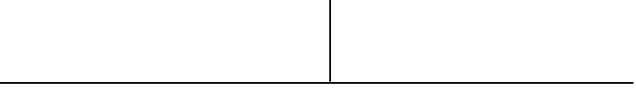

Rev. Latinoam. Psicopat. Fund., São Paulo, v. 11, n. 4, p. 562-572, dezembro 2008

\title{
Conservadorismo religioso e "Moisés e o monoteísmo", de Sigmund Freud - uma abordagem que ainda surpreende*
}

Gisálio Cerqueira Filho

Para Rosa Casoy, com afeto e admiração.

A referência de Lênin à via prussiana corresponde ao período que vai da unificação alemã e passagem para o capitalismo até a conjuntura final da primeira guerra. Logo depois, dá-se o atentado contra o líder soviético, daí advindo a sua morte.

A chamada via prussiana (cf. Cerqueira Filho, 2005, cap. VII), todavia, segue presente e se revela na continuidade histórica, menos na república de Weimar e mais no regime nazista após Hitler tomar o poder. Assim, para nós, o desenvolvimento do capitalismo associado à via prus-

* Conferência proferida no III Congresso Internacional de Psicopatologia Fundamental e IX Congresso Brasileiro de Psicopatologia Fundamental, realizados em Niterói, RJ, de 4 a 7 de setembro de 2008 . 
siana se dá em dois tempos: a partir da unificação alemã e depois, no III Reich. Após a derrota na segunda grande guerra, a história já será outra. Mas o interesse permanece centrado nos afetos e emoções, sobretudo inconscientes. Um fator importante que funciona como catalisador de sentimentos, que produzem efeitos políticos, é, sem dúvida, a religião.

Está claro que o protestantismo luterano teve sua importância na Prússia e na hegemonia que assegura a unificação. Max Weber estudou o tema com vigor.

Agora, trata-se da hipótese da convergência entre o cristianismo de base luterana e o cristianismo de base católica romana, cujo principal reduto é a Baviera. Mais do que isso, como uma ideologia da velha direita (o catolicismo político austríaco), sem prejuízo das diferenças para com o luteranismo, transformou-se em ideologia de uma nova esquerda (o pensamento social cristão, aqui e ali também chamado de socialismo cristão).

Se a política é mágica, ${ }^{1}$ no sentido de incluir o registro imaginário na acepção lacaniana, estávamos, então, diante de duas mágicas. Uma tradição da velha esquerda (nacionalismo alemão grossdeutch) transformada em ideologia da nova direita (pangermanismo racista) e o inverso, o catolicismo tradicional, sobretudo ao sul da Alemanha (velha direita), transformado em socialismo cristão militante e de massas (nova esquerda). Se a primeira se deve, em grande medida, a Georg Schonerer, a segunda pode ser atribuída a Karl Lueger, que chegou a ser prefeito de Viena (1897). Mas o que estará fazendo aqui esse vienense da gema? Se o primeiro falava aos pangermanistas, este falará aos católicos, que puderam se juntar aos nacionalistas prussianos e luteranos, sem prejuízo do luteranismo nos alemães do Norte.

Mas antes de se abordar a militância de Karl Lueger, vejamos como estamos entendendo a religião. Para o período que interessa, o entendimento que Novallis e Schelling têm da religião nos basta. Ela não corresponde ao sentido comum; não se refere ao caráter histórico, nem mesmo ao enquadramento do cristianismo, se nos referimos ao Ocidente. Ambos referem-se "à arte como religião" (não haverá aqui uma inspiração maquiaveliana?) ou "à religião nos limites da arte”, onde o objetivo é, conforme F. Schlegel (apud Andrade, 2001), "a defesa das formas simbólicas e da sua necessidade contra o sentido profano” (p. 45).

Em Maquiavel (1973), um ponto alto da sua reflexão é a questão da imanência ou transcendência do Estado com relação à sociedade. A interpretação do pensamento de Maquiavel sugere que o Estado se reveste das aparências da transcendência na busca de um compromisso, de resto inviável, entre os interesses dos

1. Mote referido a Hugo von Hofmannsthal, citado em Carl E. Schorske, "Viena fin-de-siècle: política e cultura”, p. 141. 
grandes e a sobrevivência do povo. Pois bem, compartilhamos com Guilhon Albuquerque (1980) a opinião de que a base desta aparência "está em mecanismos ideológicos cuja efetividade Maquiavel aponta, na religião, o sucedâneo para o temor do Príncipe” (p. 66).

Schelling (apud Andrade, 2001) assim se expressa: “... escutamos dizer que a massa deve ter uma religião acessível aos sentidos. Não é somente a massa, mas o filósofo também a necessita. O monoteísmo da razão e do coração, o politeísmo da imaginação e da arte, eis o que precisamos” (p. 45).

Ricardo Sobral de Andrade (2001, p. 46-47) ressalta que há neste projeto religioso uma proposta bíblica, de uma bíblia-enciclopédia (iluminista), simultaneamente um projeto editorial no âmbito da arte da produção literária, representando as intenções de criação de uma obra de arte absoluta. O projeto bíblico-enciclopédico cria uma passagem da epistemologia para uma religião que, por sua vez, se consumará numa estética. Esse movimento religioso será denominado de pietismo.

No século XVII, o pietismo reflete um descontentamento em relação aos rumos do protestantismo luterano, mas ainda uma reação à ortodoxia que, de certo modo, adulterava o espírito da piedade cristã pregado por Lutero. Nesse aspecto, o pietismo pode e deve ser considerado como uma reforma dentro da reforma. Ele terá um caráter ecumênico e não se estrutura em linha de ruptura com as igrejas estabelecidas. O pietismo terá uma importância crucial no desenvolvimento da cultura germânica. Podemos listar alguns personagens que sofreram sua influência: entre outros, Kant, G. H. Schubert, Moisés Mendelsohn, Schleiermacher, Novallis, Goethe e mesmo Sigmund Freud. Em Goethe, por exemplo, o pietismo será significativo no seu Os anos de aprendizagem de Wilhelm Meister. Tornando-se peça-chave da estética romântica, o livro VI, “Confissões de uma bela alma”, é o capítulo religioso do romance, mas sobretudo um formidável documento sobre o pietismo e seus desdobramentos na Alemanha.

A partir da compreensão de que o pietista é o artesão da própria fé (a idéia presente é a de que a salvação está ligada à fé pessoal de cada qual) o movimento religioso pode ser visto em três fases.

A primeira fase inicia-se com Philip Jacob Spener (1635-1707), pastor em Frankfurt e inspirador do movimento. Nesta época defende-se a leitura da Bíblia em pequenos grupos, Ecclésiolia in Ecclésia (pequena igreja na grande). Seguiase então a interpretação bíblica e discussão das diversas passagens. Esses grupos se difundem especialmente entre a aristocracia e a alta burguesia. Mais tarde, Spener será nomeado pastor da corte em Dresden e exercerá influência na Universidade de Leipzig, onde realiza uma aproximação entre o ensino acadêmico e a religião. 
A segunda fase é a da organização do pietismo, que muito deve a August Herman Francke (1633-1727). Este receberá o apoio de Frederico de Bradenburgo, rei da Prússia em 1700. A universidade de Halle será transformada num centro de pesquisa, divulgação e ensino do pietismo. De Halle e a partir do relato de revelação escrito por Francke, teremos, de um lado, o chamado "método Halle" (a prática de relato do encontro de cada qual com a revelação) e, de outro, a combinação, no marco iluminista assinalado pelo projeto da bíblia-enciclopédia, da reflexão racional com o espírito místico e o humanismo clássico (surgem as primeiras traduções de Homero e Horácio na Alemanha). Datam dessa época a experiência religiosa de "conversa com Deus" e do "exame de consciência” que com certeza exerceram influência no pensamento freudiano e na emergência da psicanálise.

A terceira, e última fase do pietismo estará referida ao conde Zizendorf (1700-1760). Educou-se em Halle, e, após receber alguns pastores exilados da Morávia, fundou um instituto pedagógico para jovens aristocratas com um orfanato e um pensionato. A marca que Zizendorf deixará será fundamental na aproximação com os elementos do catolicismo que serão advindos através do quietismo, movimento paralelo ao pietismo que evolui no interior da Igreja católica romana. O protestantismo, em virtude de sua aproximação com o quietismo, inclusive o culto à Virgem e às imagens, permitirá a reintrodução das imagens e ícones na Alemanha reformada. Isto terá enorme importância na edição do projeto bíbliaenciclopédia pela profusão dos desenhos e imagens que passarão a ser veiculados. A partir desse ponto, o pietismo (protestante luterano), já convergindo com o quietismo (católico romano), se aproximará do judaísmo. Isto se dará por intermédio do filósofo Moisés Mendelsohn, pai de Dorothea Mendelsohn, esposa de Friedrich Schelegel. Liberalismo e ecumenismo religioso que acabarão expressos pela tradução do Pentateuco, tarefa que é levada a cabo por Moisés Mendelsohn. Uma das conseqüências da obra de Mendelsohn é a tradução da Bíblia pelos irmãos Ludwig e Phöbus Philippson, conhecida como a Bíblia de Philippson, que será uma bíblia judaica romântico-pietista com alguma influência quietista. Esta será a bíblia lida por Freud, a partir da sugestão e ensino paternos. Ela teve sucessivas edições em 1844, 1858 e 1878.

Provisoriamente deixemos de lado a ponte ecumênica percorrida por Moisés Mendelsohn e voltemos à relação luteranismo e catolicismo romano via pietismo e quietismo. Por quê? Porque aí está o eixo da aproximação entre a religião luterana dos alemães do Norte (Prússia) e o catolicismo romano dos alemães do Sul (Baviera). Como a hegemonia de passagem ao capitalismo na Alemanha é prussiana, muito nos interessa verificar como se dá a adesão dos católicos a esta hegemonia (no quadro da unificação política). Para isto seria necessário que a ideologia tradicional do catolicismo se transformasse numa militância social-cristã. 
Isto ocorre no império austríaco pelas mãos de Karl Lueger, cujo apelido schöne Karl (o belo Carlos) já é sintoma da sua sedução e magia. A "bela alma” de Wilhelm Meister falará pelo "belo Carlos”: “meu espírito ativo não podia dormir nem sonhar, eu sentia, eu pensava, eu adquiri pouco a pouco a faculdade de conversar com Deus sobre meus sentimentos e meus pensamentos” (Goethe, 1983, p. 27).

Karl Lueger não era nacionalista exaltado e, muito menos, pangermanista, como Georg Schonerer. Trazer os católicos austríacos para a casa doméstica do Hofburg de Viena e, a partir daí, que os novos ventos da política levassem a boa nova para os luteranos prussianos.

A ideologia nacional-socialista fez o resto, amalgamando ressentimentos, anti-semitismo, anticomunismo, fundamentalismo - inclusive religioso antiliberalismo e autoritarismo. Carl Schmmitt (1998) foi um poderoso porta-voz no campo do direito e da política.

\section{II}

“Moisés e o monoteísmo” (Freud, 1939[1934-38]), como sabemos, foi escrita em três tempos. Os dois primeiros dos três ensaios que constituem esta obra apareceram originalmente em 1937 em Imago, 23 (1), p. 5-13 e (4) p. 387-419. Sabe-se que o primeiro rascunho foi escrito durante o verão de 1934 e o título então previsto era “O homem Moisés, um romance histórico”. Já o terceiro ensaio foi lido por Anna Freud no Congresso Internacional de Paris, em 2 de agosto de 1938.

Freud fala claramente do quanto deixa a imaginação se apoderar desse seu escrito; chega a dar conta de uma certa arbitrariedade e até inescrupulosidade com relação à fonte bíblica. Recorda ser um homem idoso que poderia inclusive não estar à altura da tarefa à qual se propõe. Mas não desiste facilmente.

Para o que nos interessa, em especial a hipótese de que Moisés pudesse ser egípcio, e não judeu, cumpre assinalar o quanto Freud recorre menos à dedução e indução e mais, muito mais, aos procedimentos abdutivos, ${ }^{2}$ num enfoque muito próximo daquele observado por Carlo Ginzburg. ${ }^{3}$

De fato, em especial no que se refere ao terceiro ensaio, Freud ultima-o em Londres, no contexto de sua transferência forçada para a Grã-Bretanha, num

2. Para uma interessante discussão sobre abdução, ver Humbert Eco e Thomas Sebeok (Orgs.). O signo de três: Dupin, Holmes, Peirce.

3. Entre outros títulos, ver Carlo Ginzburg. Relações de força: história, retórica, prova. 
momento de crescimento vertiginoso do nazismo e mesmo do fundamentalismo na política, mas crescentemente também em campos conexos, como a arte, cultura, religião (Edmundson, 2007). Freud estava então travando uma luta tenaz pela vida e se permitia imaginar à solta em termos de audácia intelectual, persistência e coragem, qualidades que ele via reunidas na figura do grande líder semita, Moisés. Na mesma perspectiva que já considerara a figura do herói Aníbal, embora este nunca tenha conseguido conquistar Roma. De certo modo, Freud se via também como um pesquisador do psiquismo dotado das mesmas virtudes que enxergava nos líderes semitas Aníbal e Moisés.

A hipótese de Freud é simples e provocativa; a de que o fundador do judaísmo não era judeu e que o judaísmo começou nos domínios do monoteísmo egípcio e não judeu. Pensando e agindo assim, com um desassombro intelectual invulgar, Freud não era apenas imaginativo. De fato, ele enfrentava os seus padecimentos, já tão próximo da morte e aos cuidados de Anna, com denodo e perspectiva histórica. Dedicar-se a esse projeto parecia dar um sentido especial à sua própria vida.

Muitos não viram com bons olhos a tese freudiana sobre Moisés. Assim foi com o teólogo judeu Martin Bubber; também com Abraham Yahuda, vizinho em Elsworthy Road, que chega a sugerir a não-publicação do livro. Padre MacNabb, do London's Catholic Herald, exclama: Inglaterra generosa e livre! Que recebe tão bem o autor de uma obra tão escandalosa! (Edmundson, 2007).

Entretanto, Freud não era de fazer concessões, nem com os outros, nem para consigo; sobretudo, quando estava convencido do seu pensamento. Freud, de fato, abria uma fenda formidável visando a uma certa acomodação de vários ancestrais não judeus do judaísmo. Ao "escavar a identidade judaica, Freud insistiu em que ela não teve início em si mesma, mas sim em outras identidades (egípcia e árabe), e percorreu um longo caminho para a descobrir” (Said, 2007, p. 73).

A visão que Freud tem é extremamente original e mesmo desafiadora. Ele pensa a figura de Moisés como alguém de dentro (insider) e de fora (outsider) ao mesmo tempo. Trata-se rigorosamente de um pensamento dialético, que abriga a noção hegeliana da "negação da negação", a despeito da visão eurocêntrica que a conjuntura histórica vienense não lhe permitiu ultrapassar.

Edward Said (2004, p. 43-85) visa retirar todas as conseqüências dessa famosa observação de Freud, muitas vezes, um tanto esquecida. A principal delas está em combater qualquer idéia de pureza, isto é, de "identidade pura”, seja do ponto de vista étnico, nacional ou religioso. Isso é história para utilizar a famosa expressão de Walter Benjamin, agarrando uma memória "tal como ela relampeja num momento de perigo” (Rose, apud Said, 2004, p. 95). 
"Pois irrecuperável é a imagem do passado, que se dirige ao presente, sem que esse presente se sinta visado por ele” (ibid., p. 95). Said nos apresenta um Freud "no presente, ou melhor, de uma forma que poderá somente lembrar como Freud foi e como não foi ouvido em seu próprio tempo... Ele nos oferece um Freud ao presente, para um mundo, ou, ao menos para uma pequenina lasca de terra no mediterrâneo oriental que se recusa a escutar” (Benjamin, apud Rose, 2004, p. 95).

Embora muitos autores tenham ressaltado que Freud não estava preocupado com a questão do colonialismo, tão presente em seu tempo, o fato é que uma forte diferenciação se impunha na relação colonizador versus colonizado. Um pouco mais tarde, Frantz Fanon (1979) daria ênfase à questão da subjugação colonial, e em 11 de julho de 1996, na Câmara dos Lordes, em Londres, o líder sul-africano Nelson Mandela diria alto e bom som este fragmento de Shakespeare (“Coriolano"): nosso sofrimento é um gozo para eles. Que ironia!

Todavia, mesmo no interior dos estados nacionais europeus, desde o século $\mathrm{XV}$, o que afetou de maneira indelével, inclusive o processo colonizador brasileiro, foi o fato de buscarem-se sociedades (colônias) bem "delimitadas e caracterizadas quer por precisas definições territoriais, quer por características sociais 'puras' em oposição a características 'impuras' ou miscigenadas e exóticas” (Berlinck, Koltai, Canongia, 2001, p. 22).

Ora, o Brasil se constitui como objeto de desejo do colonizador, mas também como “negativo do projeto de 'pureza' e de 'civilização' exatamente para assegurar este sonho irrealizável de 'pureza' e de 'civilização' que desemboca, afinal, no nazismo e na Segunda Guerra Mundial” (ibid., p. 22).

Uma tal concepção de pureza não tolerará o Outro, necessitando obsessivamente eliminá-lo. A quimera do europeu sem preconceito se assenta, pois, na capacidade de eliminar o outro em nome da pureza. Ao americano, por seu turno, resta o preconceito ou a miscigenação; muitas vezes como algo exótico. Não há como se imaginar uma 'identidade nacional' brasileira, "a não ser como um sonho de intelectuais ou como enigma perseguindo os estudiosos do Brasil. Mistério este que pode levar "a ricos estudos de nossa gente e de nossa cultura (ibid., p. 22).

Daí o oportuno título do filósofo esloveno Slavoj Zizek (2007) numa de suas recentes palestras internacionais: Fear Thy Neighbor as Thyself.

Ora, o que Edward Said pretende ao resgatar a abdução conclusiva de Freud de que Moisés não era judeu ${ }^{4}$ é trazer à tona, na contemporaneidade, o quanto a

4. De resto já presente em Yosef Haym Yerushalmi, O Moisés de Freud: judaísmo terminável e interminável. 
legislação do atual Estado de Israel reprime e cancela cuidadosamente a abertura de Freud, da identidade judaica em relação ao seu passado não judeu.

Qual a importância de uma hipótese que subtrai ao judaísmo qualquer conotação de pureza? Manoel Berlinck et al. (2001) sublinham:

Quando o eu encontra-se estruturado tendo por base um ideal de pureza, tende para uma integridade protetora das eventuais invasões do outro. Nesta circunstância, como já foi observado, o outro tende a ser eliminado do espaço do eu. Quando, em contrapartida, o eu é concebido e idealizado como impuro ou sujeito à miscigenação, as invasões do outro como parte tornam-se freqüentes e poderosas, e a multiplicidade pode acabar por constituir um corpo “esquizofrenizado". (p. 25-26)

Como Freud se credenciou para essa aventura abdutiva ao cruzar realidade e ficção no que concerne ao tratamento da judeidade de Moisés? Freud estava embebido na cultura clássica; desde o início de sua vida intelectual foi um apaixonado pela Antiguidade: Egito, Grécia, Roma. Era um erudito, que lera com avidez Jacob Burckhardt, História da cultura grega. Esquecia-se do mundo com sua coleção de objetos antigos e referidos aos deuses primevos, mitos, religiões, há muito esquecidas. Esses objetos acabaram por adornar o escritório da Bergasse, 19 e foram testemunhas da ventura vienense... (Gay, 1994). Sempre tivera o desejo de ter Roma a seus pés, numa alusão ao desejo irrealizado de Aníbal e, como dissera então, com o interesse de mapear um pouco da cultura católica romana à qual fora introduzido por uma babá de origem tcheca. Desde garoto, tinha uma paixão, como muitos da sua idade, pela arqueologia e, em especial, por Heinrich Schliemann, descobridor de Tróia. Chegou a cultivar amizade com o professor Emanuel Löwy, da Universidade de Viena, especialista em arqueologia.

A metáfora da arqueologia sempre funcionou para Freud como expressão para a escavação do psiquismo humano, sua paixão (Kuspit apud Gay, 1994). Assim, a sua reflexão apontava também para o quanto do nosso conhecimento do passado é sem garantias, “inevitavelmente incerto, descontínuo, lacunar: baseado numa massa de fragmentos e de ruínas” (Ginzburg, 2008, p. 40).

Ao longo de toda a vida, Freud cultivou a capacidade de mudar, de retificar suas teorias, revisar seus pensamentos; utilizava-se com freqüência dos procedimentos típicos da ciência positivista e tão recorrentes em Galileu Galilei. Colocava as suas próprias idéias, antes de tudo, sob o crivo de uma crítica implacável, recorrendo freqüentemente a um estilo literário de diálogo com um suposto "advogado do diabo". Todavia, aferrava-se ao menor indício, quando este podia converter-se em rastro, sinal, enfim sintoma que, na repetição, expandia-se no seu esplendor. Em várias oportunidades Freud manifestou o pensamento de que o "sentido da vida era dado pela morte". Um paradoxo 
admirável, que o objetivo da vida - toda uma vida - orgânica, psíquica, social, fosse precisamente a morte. No idioma inglês, Mark Edmundson (2007, p. 18) nomeou esta particularidade com a expressão Death Drive. No sentido de a morte dirigir a vida.

Até o seu último suspiro, esta foi uma hipótese em aberto. Do seu ponto de vista, Sigmund Freud simplesmente correu contra o tempo para, com base em tão poucas evidências propostas pela ciência positivista, construir uma idéia que pudesse contradizer todo e qualquer fundamentalismo, em qualquer campo que ele se manifestasse, inclusive, e sobretudo, o da cultura religiosa.

Em Freud a categoria da morte não corresponderia exatamente ao fim ou à anulação da vida. Supunha a categoria da morte referida à dimensão (imortal) da subjetividade que transcende a vida, ou a mera existência celular. O filósofo esloveno Slavoj Zizek (2001) sustenta "que a vida humana nunca é apenas vida, mas - ao contrário - é sempre sustentada por um excesso de vida” (p. 104). Esse excesso de vida é a pulsão de morte. E é no contexto dela que tanto Freud, mas sobretudo Jacques Lacan, inscrevem a motivação humana com respeito ao gozo (jouissance); uma compulsão básica de atingir a satisfação consumada e tamponar assim a ferida aberta na ordem do ser (Zizek e Daly, 2006). ${ }^{5}$

\section{Referências}

Andrade, R. S. A face noturna do pensamento freudiano. Niterói: Eduff, 2001.

Benjamin, B. Magia e técnica, arte e política. São Paulo: Brasiliense, 1995.

Berlinck, M.T.; Koltai, C.; Canongia, A.I. Esquizofrenia e miscigenação. Revista Latinoamericana de Psicopatologia Fundamental, São Paulo, v. IV, n. 4, p. 11-29, dez. 2001.

Cerqueira Filho, G. Autoritarismo afetivo: a Prússia como sentimento. São Paulo: Escuta, 2005.

Есо, Н.; Sевеок, T. (Orgs.). O signo de três: Dupin, Holmes, Peirce. São Paulo: Perspectiva, 1983.

Edmundson, M. The death of Sigmund Freud. Great Britain: Bloomsbury, 2007.

FAnon, F. Os condenados da terra. Rio de Janeiro: Civilização Brasileira, 1979.

5. Especialmente a introdução de Glyn Dalyn, p. 7-33 e, em particular, p. 10. 
Freud, S. (1939[1934-38]). Moses and Monotheism: Three Essays. In: SE. London: The Hogart Press and the Institute of Psychoanalysis, 1953-74. v. XXIII.

. (1939[1934-38]). Moisés e o monoteísmo. In: Edição Standard Brasileira das Obras Psicológicas Completas de Sigmund Freud. Rio de Janeiro: Imago, 1976. v. XXIII.

GAY, P. Introdução. In: Sigmund Freud e arqueologia: sua coleção de antigüidades. Rio de Janeiro: Salamandra, 1994.

GinzBurg, C. Relações de força: história, retórica, prova. São Paulo: Companhia das Letras, 2002.

2008.

. O fio e os rastros: verdadeiro, falso, fictício. São Paulo: Companhia das Letras,

Goethe, J.W. Les années d'apprentissage de Wilhelm Meister. Paris: Aubier-Montaigne, 1983.

Guilhon Albuquerque, J.A. Metáforas do poder. Rio de Janeiro: Achiamé/Socii, 1980.

Kuspit, D. Uma metáfora poderosa: a analogia entre a arqueologia e a psicanálise. In: Sigmund Freud e arqueologia: sua coleção de antigüidades. Rio de Janeiro: Salamandra, 1994.

Maquiavel, N. O príncipe. Rio de Janeiro: Abril, 1973. (Os Pensadores).

Rose, J. Resposta a Edward Said, no Museu Freud, em Londres, em dezembro de 2001. In: SAID, E. Freud e os não-europeus. São Paulo: Boitempo, 2004.

SAID, E. Conferência realizada no Museu Freud, em Londres, em dezembro de 2001. In: Freud e os não-europeus. São Paulo: Boitempo, 2004.

Schlegel, F. "L'Athenaeum”, Dresde, 1798. v. I.

Schelling, F.W. Le plus anicen programme systematique de l'idealisme allemande. In: Chalenger, J. Schelling et la realité finie. Paris: PUF, 1966.

Sснмітт, C. (1925). Catolicismo romano e forma política. Lisboa: Hugin, 1998.

Schorske, C. E. Viena fin-de-siècle: política e cultura. São Paulo: Companhia das Letras, 1989.

Yerushalmi, Y.H. O Moisés de Freud: judaísmo terminável e interminável. Rio de Janeiro: Imago, 1992.

ZızeK, S. On Belief. London: Routledge, 2001. . Fear Thy Neighbor as Thyself, University of New Mexico (UNM). USA, Brian O’Neil Memorial Lectures Series, n. 30, nov.2007. 
ZızeK, S.; DaLy, G. Arriscar o impossível: conversas com Zizek. São Paulo: Martins Fontes, 2006.

\section{Gisálio Cerqueira Filho}

Doutor em Ciência Política pela Universidade de São Paulo - USP (São Paulo, SP, Brasil), com pós-doc. na Biblioteca Nacional de Lisboa, Portugal; Professor Associado de Ciência Política na Universidade Federal Fluminense - UFF (Niterói, RJ, Brasil); pesquisador senior da Associação Universiotária de Pesquisa em Psicopatologia Fundamental (São Paulo, SP, Brasil); Professor Titular de Sociologia na Universidade Federal Fluminense - UFF (Niterói, RJ, Brasil); membro do Laboratório Cidade e Poder do Programa de Pós-graduação em História, da Universidade Federal Fluminense - UFF (Niterói, RJ, Brasil).

Rua Bom Pastor, 107/901 - bloco 1 - Tijuca

20251-060 Rio de Janeiro, RJ

Fone: (21) 2254-6936

e-mail: gisalio@superig.com.br 